\title{
An unusual cause of iron deficiency anemia in a healthy man: Hijamah
}

\section{Sağllklı bir erkekte demir eksikliği anemisinin nadir görülen bir nedeni: Hijamah}

\author{
Remzi Adnan Akdoğan¹, Elif Akdoğan² \\ ${ }^{1}$ Department of Gastroenterology, Rize Education and Research Hospital, Rize, Turkey \\ ${ }^{2}$ Department of Hematology, Rize Education and Research Hospital, Rize, Turkey
}

Bloodletting with cupping is used by numerous populations throughout the world. There is an Islamic basis for this type of therapy, which is known as hijamah. Hijamah is a process of removing blood from the skin, and is thought to enhance health, detoxify the body, and enhance immunity; however, blood loss from the skin may occur with voluntary incisions and bloodletting with cupping.

A 50-year-old man presented to our hospital with fatigue. A medical review of systems was negative for other symptoms. The patient's history of serious illnesses, hospitalization, and major surgery was negative. Although he had no complaints, he had been performing bloodletting with cupping for 4 years in an effort to improve his health. Physical examination showed signs of variably sized incisions and suction marks on his back and abdomen (Figures 1-3). His conjunctivas and skin were markedly pale.

The patient's initial findings were as follows: hemoglobin level: $3.6 \mathrm{~g} / \mathrm{dL}$; hematocrit level: 16.4\%; mean corpuscular volume: $50 \mathrm{fL}$; mean corpuscular hemoglobin concentration: $21.9 \mathrm{~g} / \mathrm{dL}$; platelet count: $852,000 / \mu \mathrm{L}$. The patient was diagnosed as iron deficiency anemia. The iron level was $22 \mathrm{ng} / \mathrm{dL}$, total iron binding capacity was $581 \mathrm{ng} / \mathrm{dL}$, ferritin was
$0.99 \mathrm{ng} / \mathrm{mL}$, and reticulocyte count was $2 \%$. Peripheral blood smear showed microcytic hypochromic anemia with anisocytosis (Figure 4). Electrolytes, vitamin B12, folate level, and routine serum analyses were normal. Fecal occult blood testing was performed 3 times and the results were negative. Even though the patient's hemoglobin and biochemical analyses were normal before performing hijamah, endoscopy and colonoscopy were offered to the patient for differential diagnosis, but we couldn't perform the procedures because of the social medicine problems. Written informed consent was obtained from the patient.

Iron deficiency anemia in men is not as common as in women and children, and it is generally associated with blood loss. Patient must be evaluated specifically for benign and malign gastrointestinal disorders [1]. Cupping is a popular alternative medicinal practice in East Asia, but is rare in Islamic countries. Bloodletting with cupping is a widely used therapeutic method in Chinese medicine. The procedure dates back several thousand years. There are several types, including cupping, bloodletting with cupping, and moving cupping. Cupping practitioners usually heat the cup with a flame to achieve 


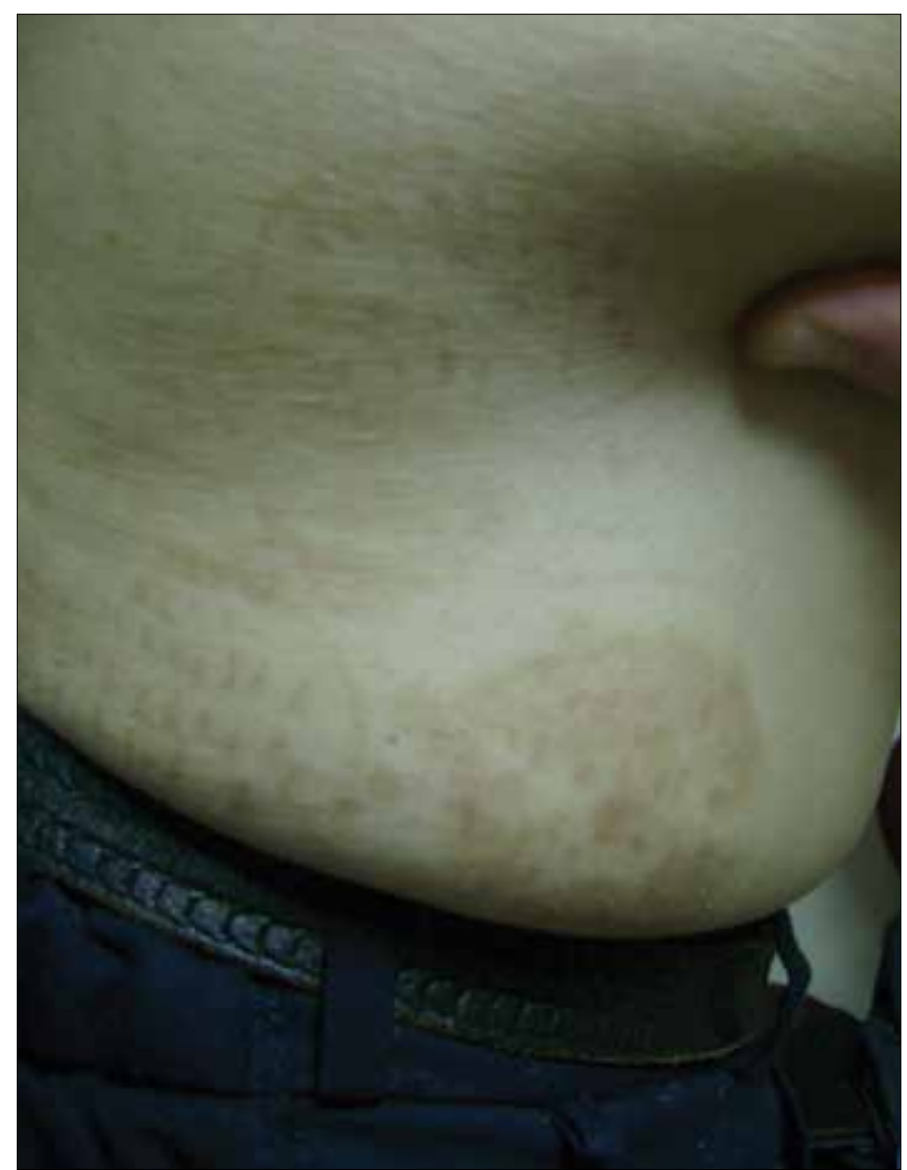

Figure 1. Signs of incisions and suctions on the skin

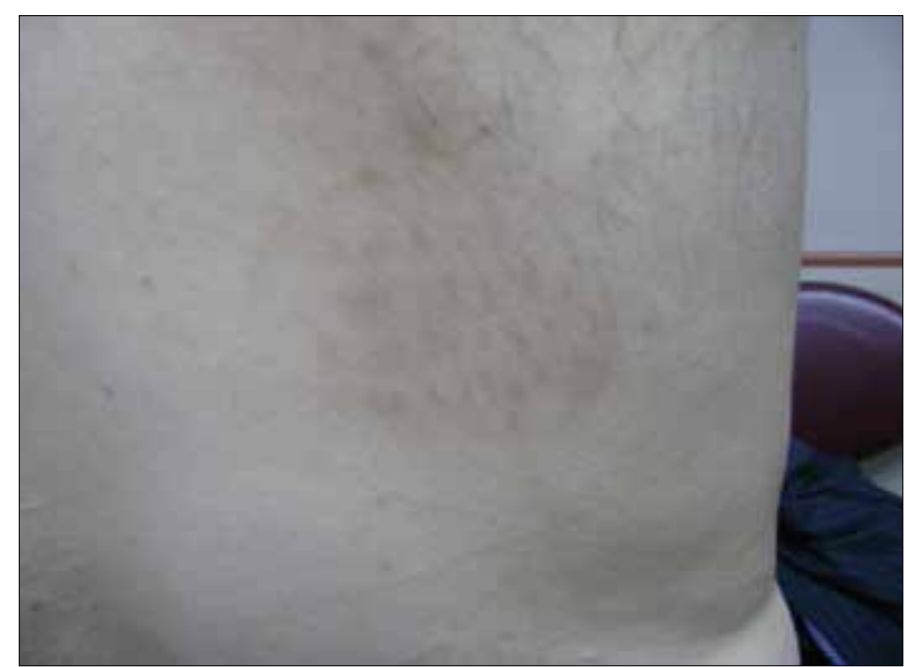

Figure 3. Signs of incisions on the skin

suction and negative pressure inside the cup. Another method of cupping is bleeding cupping, as used by the presented patient. First, practitioners make small incisions and after bleeding occurs they create negative pressure suction in the cup. Cuppingbased therapies are used for a variety of diseases and therapeutic purposes [1].

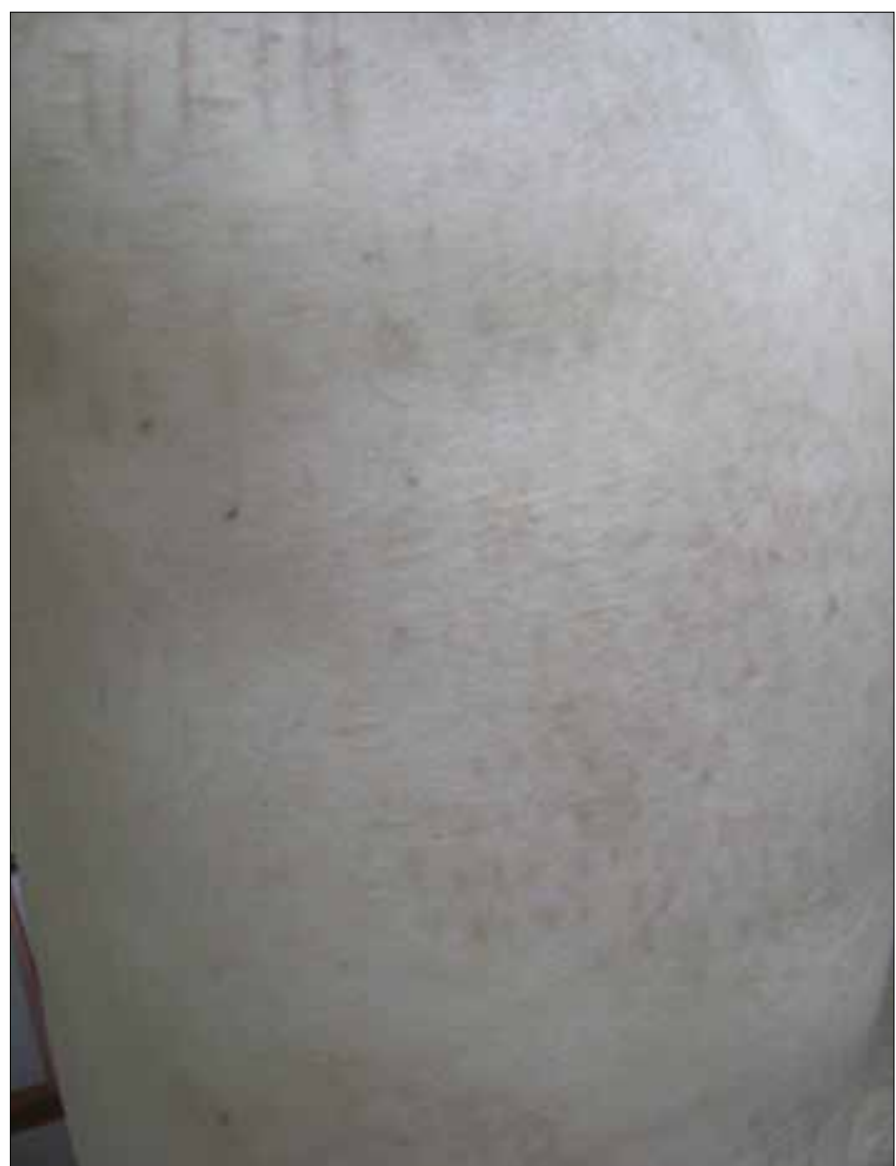

Figure 2. Signs of incisions on the skin

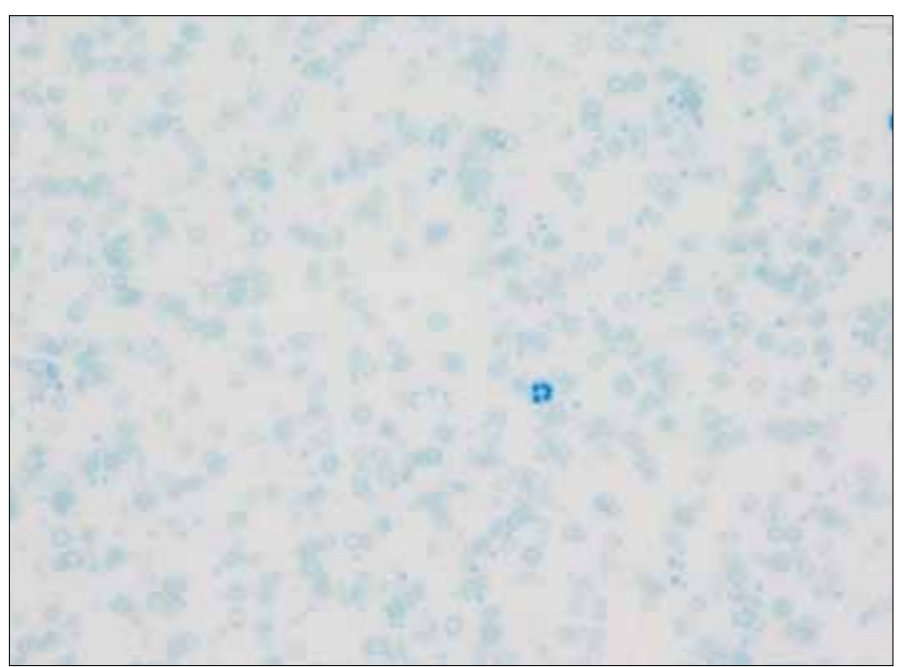

Figure 4. Peripheral blood smear

The literature contains several case reports from East Asia. One such report describes reversible cardiac hypertrophy in a patient with severe chronic anemia due to long-term bloodletting with cupping and another describes cupping therapy induced iron deficiency anemia [2,3]. In the presented case blood loss from the skin was caused by self-made 
incisions and bloodletting with cupping. Even though the presented patient had no complaints, he reported that he performed bloodletting with cupping to improve his health. To the best of our knowledge this is the first Turkish case report of iron deficiency anemia in a healthy man caused by bloodletting with cupping (hijamah).

\section{Conflict of interest statement}

The authors of this paper have no conflicts of interest, including specific financial interests, relationships, and/or affiliations relevant to the subject matter or materials included.

\section{References}

1. Cao H, Han M, Li X, Dong S, Shang Y, Wang Q, Xu S, Liu J. Clinical research evidence of cupping therapy in china: a systematic literature review. BMC Complementary and Alternative Medicine 2010;10:70.

2. Sohn IS, Jin ES, Cho JM, Kim CJ, Bae JH, Moon JY, Lee SH, Kim MJ. Bloodletting-induced cardiomyopathy: reversible cardiac hypertrophy in severe chronic anaemia from long-term bloodletting with cupping. European Journal of Echocardiography 2008;9:585-6.

3. Lee HJ, Park NH, Yun HJ, Kim S, Jo DY. CuppingTherapy induced iron deficiency anemia in a healthy man. American Journal of Internal Medicine 2008;121:e5-6. 